\title{
Statin Muscle Toxicity and Genetic Risk Factors
}

Giuliana Mombelli* and Chiara Pavanello

A.O. Ospedale Niguarda Cà Granda, Piazza Ospedale Maggiore 3, 20162 Milano, Italy

\begin{abstract}
Hydroxymethylglutaryl-CoA (HMG-CoA) reductase inhibitors (statins) can cause skeletal muscle toxicity; the risk of toxicity is elevated by drug interactions and pharmacogenetic factors that increase the concentration of statins in plasma.

The genetic basis of statin-related muscle disorders is largely unknown. Statins are substrates for several membrane transporters that may mediate drug interactions. Potent inhibitors of cytochrome P450 (CYP450) especially CYP3A4, can significantly increase the plasma concentrations of the active forms of atorvastatin, lovastatin and simvastatin. Fluvastatin, which is metabolized by CYP2C9, is less prone to pharmacokinetic interactions, while pravastatin and rosuvastatin are not susceptible to any CYP inhibition. OATP1B1 can decrease the hepatic uptake of many statins, as well as the therapeutic index of these agents. Polymorphisms of CYP450 enzymes, SLCO1B1, $A B C B 1$, and $C O Q 2$ gene, can induce statin intolerance. This review summarized the principal relations known between statin myotoxicity and genetic risk factors.
\end{abstract}

Keywords: Statins; CYP450; SLCO1B1; ABCB1; COQ2; Genetic risk factors; Myopathy

\section{Introduction}

Statins are a widely used group of drugs which are effective in reducing cardiovascular risk, largely by reducing low-density lipoprotein cholesterol (LDL-C) concentrations [1].

Although, statins are generally well tolerated and have a good safety profile, adverse drug reactions (ADRs), such as muscle toxicity may occur in some patients [2].

The prevalence of statin-related myopathic symptoms has increased with the frequency of statin use, and their incidence has increased with the use of higher doses.

In the clinical trials, the statin discontinuation rate due to ADRs ranges between 1 and 5\% [3].The common ADRs reported include gastrointestinal complaints, rashes, dizziness, pruritus and headache [4].

Statin-related skeletal muscle disorders include: non-specific muscle aches or joint pains without elevated serum creatinine kinase (CK), or myopathy with elevation of serum CK.

At present, the literature support three diagnostic levels:

1) incipient myopathy (CK above 3-fold the upper limit of normal (ULN), less than 10-fold the ULN). ULN).

2) myopathy (CK above 10-fold the ULN, less than 50-fold the

3) rhabdomyolysis (CK above 50-fold the ULN) $[5,6]$.

In the context of statin monotherapy, the frequency of myopathy is $\sim 1 / 1,000$, and the frequency of rhabdomyolysis is $\sim 1 / 100,000$. The frequency increases with dose $[7,8]$. Clinicians often measure serum CK levels, as parameter of severity, but the correlation between symptoms and CK level is incomplete. Therefore, the clinical interpretation of CK level is complex. Elevations less than three-fold the ULN are typically of little consequences. Conversely, the physician often changes the dose or the therapy when the levels increase 3-fold the ULN.

The CK level is the most important marker to evaluate the muscle damage, but, there are other potential, a specific marker of myotoxicity i.e. the increase of aldolase and lactate dehydrogenase in the serum. Statin tolerability is modified by several genetic factors. Some genetic variations associated to statin myotoxicity have been described [9], and include polymorphisms in CYP450 enzymes that accomplish the oxidation of most statins (phase I metabolism), polymorphisms in membrane transporters altering the cellular uptake of statins, for example, in the solute carrier organic anion transporter (SLCO) family (influx transporter), in ATP-binding cassette (ABC) family (efflux transporter), and polymorphisms in the COQ2 gene (encoding the second enzyme of coenzyme Q10 (CoQ10) biosynthesis) [10].

Muscle toxicity related to statin use may be influence by genetic factors (presence or absence of specific genotypes). Genetic risk factors contribute to the development of statin-induced myopathies by drugmetabolism or muscle-metabolism $[11,12]$.

Several studies have provided increasing evidence that genetic factors may contribute to statin myopathy, and it has been suggested, that the pharmacogenomic analyses, probably, may give in the future the possibility, to identify susceptible individuals $[13,14]$. This review provides an update on alleged genetic risk factors, related to muscular disorder with statins intake.

\section{Genetic Risk Factors for Statin Myopathy}

\section{Variants of CYP450}

CYP3A4 is the main pathway via which statins (simvastatin, atorvastatin and lovastatin) undergo phase I metabolism. The activity of the CYP3A4 gene can vary up to 10 -fold between patients, therefore affecting the efficacy and tolerability of statin therapy.

*Corresponding author: Giuliana Mombelli, A.O. Ospedale Niguarda Cà Granda Piazza Ospedale Maggiore 3, 20162 Milano, Italy, Tel: +390250319904, Fax: +39 0264444513, E-mail: giuliana.mombelli@ospedaleniguarda.it

Received August 29, 2013; Accepted October 08, 2013; Published October 18 2013

Citation: Mombelli G, Pavanello C (2013) Statin Muscle Toxicity and Genetic Risk Factors. Int J Genomic Med 1: 111. doi: 10.4172/2332-0672.1000111

Copyright: @ 2013 Mombelli G, et al. This is an open-access article distributed under the terms of the Creative Commons Attribution License, which permits unrestricted use, distribution, and reproduction in any medium, provided the original author and source are credited. 
The cytochrome enzyme system is the most important enzyme system responsible for phase 1 metabolism of various statins, with more than 30 known isoenzymes [13].

Phase I oxidation by the CYPs is relevant for almost all statins, except pitavastatin, fluvastatin and rosuvastatin [14]. The major CYPs, i.e. CYP3A4, CYP3A5, CYP2D6 and CPY2C9 are all involved in statin metabolism.

Particular interest is in CYP2D6, CYP3A4/5, all affected by genetic variants, which can vary their function (Table 1). CYP3A4 is the major route of metabolism of statins. Conversely CYP2D6 and CYP3A5 are not the more important enzymatic pathways involved, but, many studies suggest that their genetic variations may contribute to highlight inter-individual differences in relation to response and ADRs in some statins [15]. CYP2D6 plays a fundamental role in the metabolism of simvastatin [16]. Mutations and alleles of the CY2D6 gene and frequencies in the European population were evaluated: these authors identified 48 point mutations, of which 29 new, thus allowing to classify patients into extensive metabolizers (EM), poor metabolizers (PM) and ultra-extensive metabolizers (UM) with inter-racial differences in the distribution of the allelic variants [17]. Carriers of allelic variants leading to inefficient drug metabolism were in fact shown to display a reduced hypocholesterolemic activity and, in addition, a higher incidence of side effects [18]. It should be noted that $5-10 \%$ of Caucasians are PM vs $<1 \%$ of Asian [19]. The CYP2D $6^{*} 4$ polymorphism may be associated with atorvastatin in addition to simvastatin-induced myopathy [20]. A proportion of patients who were prescribed atorvastatin therapy and were reported to have experienced a muscle side effects, expressed the CYP2D6 ${ }^{*} 4$ variant gene (50\%) [20]. Muscle events noted were myalgia (defined in this cases muscle pain/ache without elevations in CK levels), myopathy (defined as muscle ache/ pain, cramps with elevation in CK levels) and rhabdomyolysis (defined as elevations in CK levels $>10$-fold the ULN). In the control group (i.e. those who were not prescribed atorvastatin therapy), $28 \%$ of individuals expressed the CYP2D $6^{\star} 4$ polymorphism [20]. In a study of ours we noted the highest efficacy of the statin in the CYP2D $6^{\star} 1 / 4^{\star}$ and ${ }^{\star} 4 / 4^{\star} \mathrm{PM}$ patients, but we have not observed an increase of ADRs in carriers of PM [21].

Among patients who develop myalgia on atorvastatin there is also a higher percentage of homozygosis for $\mathrm{CYP} 3 \mathrm{~A} 55^{\star} 3$; these patients also display higher plasma CK levels vs. those heterozygotes [22].

\section{Variants of SLCO1B1}

Inter-individual gene expression differences of SLCO1B1 may explain part of the variability in tolerance and effect for statin treatment (Table 1). The SLCO member 1B1 gene (SLCO1B1), located on the short arm of chromosome 12, encodes for a protein called organic anion transporting polypeptide $1 \mathrm{~B} 1$, or OATP1B1. This protein is located in liver cells and in transports compounds (endogenous and xenobiotic) from the blood into the liver. Numerous studies led the discovery that this transporter is largely responsible of statin influx [23] Atorvastatin, rosuvastatin [24], simvastatin [25] and pravastatin [26] use this mechanism. Fluvastatin can easily penetrate the hepatocyte membrane because of its lipophilicity, or by using other transporter [27]

Some common variations in the SLCO1B1 gene are associated to a reduced ability to process these drugs [24].

Low-function variants of $S L C O 1 B 1$ were identified as risk factors for muscle toxicity and rhabdomyolysis due to the low hepatic influx activity of that protein. This means higher blood concentration of statins and higher muscle tissues exposure [28].
The Study of the Effectiveness of Additional Reductions in Cholesterol and Homocysteine (SEARCH) group [23] carried out a genome-wide association study (GWAS) using 300,000 markers in 85 individuals with definite or initial myopathy and 90 statin-tolerant controls, all of whom were taking $80 \mathrm{mg}$ of simvastatin daily as a part of another SEARCH Collaborative Group trial involving 12,000 participants.

This study provided definitive evidence on the role of the SLCO1B1 gene system on the occurrence of myalgia/myopathy.

The SEARCH Collaborative Group identified a strong association between myopathy and rs4363657, a single-nucleotide polymorphism (SNP) located within SLCO1B1. This non-coding rs4363657 SNP was in nearly complete linkage disequilibrium with the non-synonymous rs4149056 SNP [23]. The last one, also known as SLCO1B1 ${ }^{\star 5}$ or as c.521T $>C$, involves a single amino acid substitution (Val174Ala), that had been previously reported as associated to increased plasma concentrations of simvastatin and pravastatin $[28,29]$. The SLCO1B1 ${ }^{\star 5}$ allele is observed in $8-16 \%$ of Caucasians, $12-16 \%$ of Chinese, $10 \%$ of Japanese and 1-2\% of Africans [30].

The odds ratio for myopathy of this SNP was 4.5 for heterozygous subjects and 16.9 for CC homozygotes compared with TT homozygotes [23]. More than $60 \%$ cases of myopathy were attributed to the $\mathrm{C}$ allele. CC homozygotes have a $18 \%$ cumulative risk, with myopathy occurring primarily during the first year of treatment, whereas the CT genotype is associated with a cumulative risk of about $3 \%$ [23]. In contrast the cumulative risk of myopathy is only $0.6 \%$ among TT homozygotes.

In the Heart Protection Study this association was replicated in 10,000 treated with $40 \mathrm{mg} /$ day simvastatin, and the outcome was a relative risk of 2.6 per copy of the $\mathrm{C}$ allele [23].

The c.521C polymorphism in this gene has a large effect on the pharmacokinetics of the hydrophilic pravastatin (otherwise not metabolized by the CYP450 system) [24]. Also the sex influences pravastatin kinetics with significantly higher levels in males with the c.521CC genotype vs. males with the c.521TC or c.521TT genotypes; these SNPs are instead not associated with drug kinetics in women [25]

The same SNP has been associated with milder forms of adverse reactions with simvastatin, atorvastatin and pravastatin, even in lower doses [31]. The molecular mechanism by which this SNP induces statin myopathy was investigated and appeared related to a decreased membrane expression of OATP1B1, affecting the maximum transport velocity [32].

Studies associating the SLCO1B1 polymorphism with the kinetics of simvastatin acid and the risk of simvastatin-induced myopathy suggest that increased plasma-concentrations of active simvastatin acid is the cause of myopathy $[23,25]$. Confirming this, in a previous report, homozygous participants carriers of c.521T $>$ C SNP presented a significantly increased mean AUC of active simvastatin acid (x 3.2 fold), atorvastatin (x 2.4 - fold) and rosuvastatin (x 1.7-fold) compared with the c.521TT genotype, whereas no effect was seen for fluvastatin and simvastatin lactone $[24,25,27]$.

In the Statin Response Examined by Genetic Haplotype Markers (STRENGHT) study, 509 patients were randomized to receive atorvastatin $10 \mathrm{mg}$, simvastatin $20 \mathrm{mg}$, or pravastatin $10 \mathrm{mg}$ for 8 weeks, followed by an additional 8 -week treatment with 80,80 or $40 \mathrm{mg}$ of these statin, respectively [31]. The SLCO1B1*5 allele was significantly more frequent among 71 subjects who developed myalgia and/or discontinued treatment because of musculoskeletal ADRs. The 
authors reported that carriers of this genetic variant were at a 2 -fold relative risk of mild statin-induced ADRs, the majority of whom had normal CK levels [31].

In addition, in a large study of individuals with type II diabetes who were receiving statins, one-third of individuals with the ${ }^{\star} 5 /{ }^{\star} 15$ haplotypes of SLCO1B1 had showed musculoskeletal ADRs, at high doses of statins. The results of this study suggest that, on average, in a population treated with $\geq 40 \mathrm{mg}$ of simvastatin, only nine people would need to be treated, to result in one individual being intolerant on account of this genotype [33].

The genetic variant $S L C O 1 B 1^{\star} 15$ haplotype, was found in higher frequency in Japanese subjects who presented myopathy after receiving pravastatin or atorvastatin [34]. Contrarily to the SEARCH study, Danik et al. [35] observed in the JUPITER study, no increased risk of myalgia among users of rosuvastatin carries of rs4363657C or rs4149056C allele in SLCO1B1.

The relevance of genetic variations in SLCO1B1 has also been demonstrated in other report, where the pravastatin has induced myopathy in a Japanese individuals with a c.1628T $>\mathrm{G}$ mutation, which reduced activity of the OATP1B1 transporter [36].

\section{Variants of $A B C B 1$}

$A B C B 1$ is a member of the ATP-binding cassette (ABC) super family of proteins. Also known as P-glycoprotein (P-gp) or multidrug resistence (MDR1), it is a $170 \mathrm{kDa}$ glycosylated membrane protein expressed in various locations including the liver, intestines, kidney, brain, and testis. Generally speaking, $A B C B 1$ is located on the membrane of cells in these locations and serves to eliminate metabolites and a wide range of hydrophobic foreign substances, including drugs, from cells by acting as an efflux transporter. Due to the localization of $A B C B 1$ on specific cells, $A B C B 1$ aids in eliminating drugs into the urine or bile and helps maintain the blood-brain barrier.

The $A B C B 1$ efflux system has been less extensively studied $[37,38]$. Many statins are substrates for this efflux transporter [39]. It has been reported that the AUC of simvastatin acid and atorvastatin was increased by approximately $60 \%$ in homozygous individuals for the $A B C B 1$ c.1236T-c.2677T-c.3435T haplotype vs. homozygotes for the reference c.1236C-c.2677G-c.3435C haplotype; no effect was seen on lactones $[37,38]$ (Table 1).

Hoenig et al. [40] genotyped for C3435T 117 patients, treated with atorvastatin $80 \mathrm{mg}$ for 6 weeks. Ten of those completing the study reported myalgia.

The CC genotype of this polymorphism in $A B C B 1$ is associated with increased MDR1 expression, so a smaller response to statins, compared with the TC/TT genotype. The $\mathrm{T}$ allele was more frequent and the $\mathrm{C}$ allele less frequent in patients with myalgia. The pharmacokinetics of most statins is altered by change in the activity of another efflux protein from the same family $A B C G 2$, encoded by the $A B C G 2$ gene $[37,40]$ in particularly atorvastatin and rosuvastatin $[38,41]$.

Keskitalo et al. [38] reported that the AUC of atorvastatin increased $72 \%$, and rosuvastatin to $144 \%$ in individuals with the $A B C G 2$ c. $421 \mathrm{AA}$ genotype (rs2231142), compared with individuals with the c.421CC genotype. These reports show no clear correlations between AUC changes and muscular side effects.

Tomlinson et al. [42] in a recent study of 305 Chinese patients treated with rosuvastatin, reported a significant greater reduction in
LDL-C levels associated with the presence of a c.421CC genotype. This observation is probably explained by the higher blood concentration of this statin, which increased the myopathy risk observed in Asians [42]. All of these results demonstrate that there may be a strong genetic susceptibility to both myopathy and statin-induced myalgias in the absence of elevated CPK values. Therefore, genetic testing may provide important prognostic information.

\section{Variants of $\mathrm{COQ2}$}

CoQ10 (ubiquinone) is a key component of the mitochondrial respiratory chain and its deficiency leads to impaired energy production. CoQ10 is produced via the mevalonate pathway and because of its lipophilicity is carried in plasma by LDL and HDL.

Statins reduce CoQ10 levels in two ways: directly inhibiting the HMG-CoA reductase, enzyme of the mevalonate pathway and reducing CoQ10 transport capacity due to decrease of LDL level [43].

Some variants in COQ2 gene, which encodes for parahydroxybenzoate-polyprenyltransferase (another enzyme involved in the mevalonate pathway), are associated with CoQ10 deficiency [44].

Researchers found, in a study involving 291 patients that two genetic variants (SNP1 and SNP2) in the COQ2 gene (rs6535454 and rs4693075) and 2-SNP haplotype were in higher frequency in subjects with statin myopathy than in statin-tolerant subjects. The odd ratios of statin intolerance were 2.42 in homozygotes for rs6535454, 2.33 in homozygotes for rs4693075 and 2.58 for the haplotype of the two variants [10] (Table 1).

Recently this association was confirmed by Puccetti et al. [45], which found an odd ratio of rosuvastatin-intolerance of 2.6 in subjects carrying rs4693075, independently from the presence of a SNP in the SLCO1B1 gene. Additional genetic studies are required to confirm these observations.

\section{Discussion}

Genome-wide association (GWA) studies have detected novel associations for serious ADRs including liver toxicity and myotoxicity, improving our understanding of the mechanisms of myotoxicity of statins and the importance of genetic predisposing factors in determining individual susceptibility to myotoxicity.

Statins have a wide therapeutic index, and severe ADRs are therefore relatively uncommon [23]. The small risk of myopathy, does not exceed the benefits of statins for reducing CV events. The benefit-risk ratio of statins is favorable compared with other wellconsolidated therapies. In clinical practice, using, lipid-lowering drugs, that are efficacious at low doses, there is a real possibility to reduce, the potential myotoxic effects. Moreover, the patient characteristics and the properties of the statins themselves can influence the risk of myopathy and it is opportune evaluate these factors during treatment selection, to maximize the benefits. Nonetheless, even though the myopathy rate is low, the high prevalence of the clinical indication (hypercholesterolemia and cardiovascular disease) creates a situation in which the absolute number of ADRs is relevant.

For simvastatin, the evidence linking myopathy to rs4149056 in SLCO1B1 is of high quality, and this association has been reproduced in randomized trials and clinical practice-based cohorts. Conversely, the association of rs4149056 with myopathy has been less compelling for other statins. 


\begin{tabular}{|c|c|c|c|c|c|}
\hline References & Gene & $\begin{array}{l}\text { SNP and or polymorphism/ } \\
\text { haplotype/genotype }\end{array}$ & Drugs & Population/Study & Conclusions \\
\hline $\begin{array}{l}\text { Frudakis et al. } 2007 \text { [20] } \\
\text { Zuccaro et al. } 2007 \text { [21] }\end{array}$ & CYP2D6 & $\begin{array}{c}\text { CYP2D6* } 4 \\
\text { CYP2D6*1/4* and }{ }^{*} 4 / 4^{*}\end{array}$ & $\begin{array}{c}\text { atorvastatin/ } \\
\text { simvastatin } \\
\text { fluvastatin/simvastatin }\end{array}$ & $\begin{array}{c}\text { Case control study } \\
100 \text { hypercholesterolemic } \\
\text { patients }\end{array}$ & $\begin{array}{c}\text { CYP2D6 polymorphism may be } \\
\text { associated with statin-induced } \\
\text { myopathy. } \\
\text { The CYP2D6* } 1 / 4^{*} \text { and } * 4 / 4^{*} \mathrm{PM} \\
\text { status is not clearly associated } \\
\text { with ADRs. }\end{array}$ \\
\hline Wilke et al. 2005 [22] & СYРЗА & CYP3A5*3 homozygous & atorvastatin & $\begin{array}{l}\text { Case control study (137 } \\
\text { patients) }\end{array}$ & $\begin{array}{c}\text { Carriers developed myalgia and } \\
\text { had higher plasma CK levels vs. } \\
\text { heterozygotes. }\end{array}$ \\
\hline $\begin{array}{l}\text { Link et al. } 2008 \text { [23] } \\
\text { Voora et al. [31] } \\
\text { Donnelly et al. } 2011 \text { [33] } \\
\text { Morimotoet al. [34] } \\
\text { Danik et al. } 2013 \text { [35] }\end{array}$ & SLCO1B1 & $\begin{array}{c}\text { rs4363657 } \\
\text { non-synonymous rs4149056 } \\
\text { rs4149056/SLCO1B1*5 } \\
\text { rs4149056( Val 174 Ala) } \\
\text { rs2306283(Asp130Asn)/ } \\
\text { SLCO1B1*5/15* haplotypes } \\
\text { SLCO1B1*15 } \\
\text { rs4363657-rs4149056 }\end{array}$ & $\begin{array}{l}\text { simvastatin } \\
\text { atorvastatin/ } \\
\text { simvastatin/ } \\
\text { pravastatin } \\
\text { statins } \\
\text { pravastatin/ } \\
\text { atorvastatin } \\
\text { rosuvastatin }\end{array}$ & $\begin{array}{c}\text { SEARCH study/ ( } 80 \\
\text { cases/90 control) } \\
\text { STRENGTH Study (509 } \\
\text { patients) } \\
\text { Go-DARTS study ( diabetic } \\
\text { patients) } \\
\text { Japanese study } \\
\text { 4.404 patients of JUPITER } \\
\text { study }\end{array}$ & $\begin{array}{c}\text { CC homozygotes have an } 18 \% \\
\text { cumulative risk of myopathy } \\
\text { during the first year of treatment. } \\
\text { Carriers at 2-fold relative risk of } \\
\text { mild statin-induced side-effects } \\
\text { despite normal CK levels. } \\
\text { Ala } 174 \text { was associated with } \\
\text { higher intolerance ( OR } 2.05, \\
\text { p=0.043) } \\
\text { There was a higher frequency of } \\
\text { SLCO1B1*15 allele in Japanese } \\
\text { subjects who has presented } \\
\text { myopathy after treatment with } \\
\text { pravastatin or atorvastatin. } \\
\text { There is no increased risk } \\
\text { of myalgia in carriers of } \\
\text { rs } 4363657 \mathrm{C} \text { or rs } 4149056 \mathrm{C} \\
\text { allele. }\end{array}$ \\
\hline $\begin{array}{l}\text { Keskitalo et al. } 2008 \text { [37] } \\
\text { Keskitalo et al. } 2009 \text { [38] }\end{array}$ & $\begin{array}{l}A B C B 1 \\
A B C G 2\end{array}$ & $\begin{array}{l}\text { (c.1236T-c.2677T-c.3435T- } \\
\text { c.1236C-c.2677G and } \\
\text { c.3435C) haplotypes } \\
\text { rs2231142/(c.421AA and } \\
\text { c.421CC) genotypes }\end{array}$ & $\begin{array}{l}\text { atorvastatin/ } \\
\text { simvastatin } \\
\text { atorvastatin/ } \\
\text { rosuvastatin }\end{array}$ & $\begin{array}{l}\text { Healthy Finnish volunteers } \\
\text { Healthy Finnish volunteers }\end{array}$ & $\begin{array}{l}\text { Homozygous individuals for } \\
\text { the ABCB1 c. } 1236 \text { T-c.2677T- } \\
\text { c.3435T showed an increased } \\
(60 \% \sim) \text { in the AUC of } \\
\text { simvastatin acid and atorvastatin. } \\
\text { Carriers of the c.421AA } \\
\text { genotype, showed an increased } \\
\text { in the AUC of atorvastatin } \\
(70 \% \sim) \text { and rosuvastatin } \\
(144 \%) .\end{array}$ \\
\hline Oh et al. 2007 [10] & COQ2 & $\begin{array}{c}\text { SNP-1 rs6535454 /SNP- } \\
2 \text { rs4693075 and 2-SNP } \\
\text { haplotype }\end{array}$ & statins & $\begin{array}{l}291 \text { hypercholesterolemic } \\
\text { patients }\end{array}$ & $\begin{array}{l}\text { The COQ2 gene (rs6535454 and } \\
\text { rs4693075) and 2-SNP haplotype } \\
\text { were in higher frequency in } \\
\text { subjects with statin myopathy } \\
\text { than in statin-tolerant subjects. }\end{array}$ \\
\hline
\end{tabular}

Table 1: Summary of genetic factors influencing Statins Myopathy in different studies.

Although both the SEARCH trial and the Heart Protection Study represent randomized controlled treatment trials, the effect size for rs4149056 was lower in the latter (i.e., at the 40-mg dose) than in SEARCH (i.e., at the $80-\mathrm{mg}$ dose), underscoring the importance of dose.

In the guideline for $S L C O 1 B 1$, the authors [28] report the recommendations about the individuals with CC rs4149056 genotype. These have high myopathy risk, accordingly, when the clinician prescribes simvastatin, there is the indication to use the lower dose or a different statin. In these subjects, the CK levels should be measured frequently. Wilke et al. [28] suggest that doses of statins should be tailored to an individual's SLCO1B1 genotype so as to avoid the risk of ADRs.

The studies conducted until now, have highlighted that the genetic tests may become an integral component of personalized medicine and may influence the efficacy and safety in which medications are selected [11,12]. We have to consider that, also in the absence of severe myopathies, many patients still opt to discontinue statin therapy because of intermediate toxicity. The non-adherence to therapy could increase the burden of cardiovascular disease on our health-care infrastructure. In conclusion, additional studies are required to throw further light on the mechanisms of toxicity of the different statins, and to detect if genetic tests are useful in clinical practice to reduce the incidence of myotoxicity.

\section{References}

1. Brugts JJ, Yetgin T, Hoeks SE, Gotto AM, Shepherd J, et al. (2009) The benefits of statins in people without established cardiovascular disease but with cardiovascular risk factors: meta-analysis of randomised controlled trials. BMJ 338: b2376.

2. Armitage $\mathrm{J}(2007)$ The safety of statins in clinical practice. Lancet 370: 1781 1790.

3. Baigent C, Keech A, Kearney PM, Blackwell L, Buck G, et al. (2005) Efficacy and safety of cholesterol-lowering treatment: prospective meta-analysis of data from 90,056 participants in 14 randomised trials of statins. Lancet 366: 1267-1278.

4. Davidson MH, Robinson JG (2006) Lipid-lowering effects of statins: a comparative review. Expert Opin Pharmacother 7: 1701-1714.

5. McKenney JM, Davidson MH, Jacobson TA, Guyton JR; National Lipid Association Statin Safety Assessment Task Force (2006) Final conclusions and recommendations of the National Lipid Association Statin Safety Assessment Task Force. Am J Cardiol 97: 89C-94C.

6. Abd TT, Jacobson TA (2011) Statin-induced myopathy: a review and update. Expert Opin Drug Saf 10: 373-387.

7. Bays $H$ (2006) Statin safety: an overview and assessment of the data--2005 Am J Cardiol 97: 6C-26C. 
8. Antons KA, Williams CD, Baker SK, Phillips PS (2006) Clinical perspectives of statin-induced rhabdomyolysis. Am J Med 119: 400-409.

9. Wilke RA, Lin DW, Roden DM, Watkins PB, Flockhart D, et al. (2007) Identifying genetic risk factors for serious adverse drug reactions: current progress and challenges. Nat Rev Drug Discov 6: 904-916.

10. Oh J, Ban MR, Miskie BA, Pollex RL, Hegele RA (2007) Genetic determinants of statin intolerance. Lipids Health Dis 6: 7 .

11. Vladutiu GD (2008) Genetic predisposition to statin myopathy. Curr Opin Rheumatol 20: 648-655.

12. Peters BJ, Klungel $\mathrm{OH}$, Visseren $\mathrm{FL}$, de Boer $\mathrm{A}$, Maitland-van der Zee $\mathrm{AH}$ (2009) Pharmacogenomic insights into treatment and management of statininduced myopathy. Genome Med 1: 120.

13. Bolego C, Baetta R, Bellosta S, Corsini A, Paoletti R (2002) Safety considerations for statins. Curr Opin Lipidol 13: 637-644.

14. Neuvonen PJ, Niemi M, Backman JT (2006) Drug interactions with lipid-lowering drugs: mechanisms and clinical relevance. Clin Pharmacol Ther 80: 565-581.

15. Maggo SD, Kennedy MA, Clark DW (2011) Clinical implications of pharmacogenetic variation on the effects of statins. Drug Saf 34: 1-19.

16. Nordin C, Dahl ML, Eriksson M, Sjöberg S (1997) Is the cholesterol-lowering effect of simvastatin influenced by CYP2D6 polymorphism? Lancet 350: 29-30.

17. Marez D, Legrand M, Sabbagh N, Lo Guidice JM, Spire C, et al. (1997) Polymorphism of the cytochrome P450 CYP2D6 gene in a European population: characterization of 48 mutations and 53 alleles, their frequencies and evolution. Pharmacogenetics 7: 193-202.

18. Mulder AB, van Lijf HJ, Bon MA, van den Bergh FA, Touw DJ, et al. (2001) Association of polymorphism in the cytochrome CYP2D6 and the efficacy and tolerability of simvastatin. Clin Pharmacol Ther 70: 546-551.

19. Kim K, Johnson JA, Derendorf H (2004) Differences in drug pharmacokinetics between East Asians and Caucasians and the role of genetic polymorphisms. J Clin Pharmacol 44: 1083-1105.

20. Frudakis TN, Thomas MJ, Ginjupalli SN, Handelin B, Gabriel R, et al. (2007) CYP2D6*4 polymorphism is associated with statin-induced muscle effects. Pharmacogenet Genomics 17: 695-707.

21. Zuccaro P, Mombelli G, Calabresi L, Baldassarre D, Palmi I, et al. (2007) Tolerability of statins is not linked to CYP450 polymorphisms, but reduced CYP2D6 metabolism improves cholesteraemic response to simvastatin and fluvastatin. Pharmacol Res 55: 310-317.

22. Wilke RA, Moore JH, Burmester JK (2005) Relative impact of CYP3A genotype and concomitant medication on the severity of atorvastatin-induced muscle damage. Pharmacogenet Genomics 15: 415-421.

23. Link E, Parish S, Armitage J, Bowman L, SEARCH Collaborative Group, et al (2008) SLCO1B1 variants and statin-induced myopathy--a genomewide study. N Engl J Med 359: 789-799.

24. Pasanen MK, Fredrikson H, Neuvonen PJ, Niemi M (2007) Different effects of SLCO1B1 polymorphism on the pharmacokinetics of atorvastatin and rosuvastatin. Clin Pharmacol Ther 82: 726-733.

25. Pasanen MK, Neuvonen M, Neuvonen PJ, Niemi M (2006) SLCO1B1 polymorphism markedly affects the pharmacokinetics of simvastatin acid Pharmacogenet Genomics 16: 873-879.

26. König J, Seithel A, Gradhand U, Fromm MF (2006) Pharmacogenomics of human OATP transporters. Naunyn Schmiedebergs Arch Pharmacol 372: 432 443.

27. Niemi M, Pasanen MK, Neuvonen PJ (2006) SLCO1B1 polymorphism and sex affect the pharmacokinetics of pravastatin but not fluvastatin. Clin Pharmacol Ther 80: 356-366.

28. Wilke RA, Ramsey LB, Johnson SG, Maxwell WD, McLeod HL, et al. (2012) The clinical pharmacogenomics implementation consortium: CPIC guideline for SLCO1B1 and simvastatin-induced myopathy. Clin Pharmacol Ther 92: 112-117.

29. Niemi M, Schaeffeler E, Lang T, Fromm MF, Neuvonen M, et al. (2004) High plasma pravastatin concentrations are associated with single nucleotide polymorphisms and haplotypes of organic anion transporting polypeptide-C (OATP-C, SLCO1B1). Pharmacogenetics 14: 429-440.

30. Niemi M (2010) Transporter pharmacogenetics and statin toxicity. Clin Pharmacol Ther 87: 130-133.

31. Voora D, Shah SH, Spasojevic I, Ali S, Reed CR, et al. (2009) The SLCO1B1*5 genetic variant is associated with statin-induced side effects. J Am Coll Cardiol 54: 1609-1616.

32. Tirona RG, Leake BF, Merino G, Kim RB (2001) Polymorphisms in OATP-C: identification of multiple allelic variants associated with altered transport activity among European- and African-Americans. J Biol Chem 276: 35669-35675

33. Donnelly LA, Doney AS, Tavendale R, Lang CC, Pearson ER, et al. (2011) Common nonsynonymous substitutions in SLCO1B1 predispose to statin intolerance in routinely treated individuals with type 2 diabetes: a go-DARTS study. Clin Pharmacol Ther 89: 210-216.

34. Morimoto K, Oishi T, Ueda S, Ueda M, Hosokawa M, et al. (2004)A novel variant allele of OATP-C (SLCO1B1) found in a Japanese patient with pravastatininduced myopathy. Drug Metab Pharmacokinet 19: 453-455.

35. Danik JS, Chasman DI, MacFadyen JG, Nyberg F, Barratt BJ, et al. (2013) Lack of association between SLCO1B1 polymorphisms and clinical myalgia following rosuvastatin therapy. Am Heart J 165: 1008-1014.

36. Furihata T, Satoh N, Ohishi T, Ugajin M, Kameyama Y, et al. (2009) Functional analysis of a mutation in the SLCO1B1 gene (c.1628T>G) identified in a Japanese patient with pravastatin-induced myopathy. Pharmacogenomics J 9: 185-193.

37. Keskitalo JE, Kurkinen KJ, Neuvoneni PJ, Niemi M (2008) ABCB1 haplotypes differentially affect the pharmacokinetics of the acid and lactone forms of simvastatin and atorvastatin. Clin Pharmacol Ther 84: 457-461.

38. Keskitalo JE, Zolk O, Fromm MF, Kurkinen KJ, Neuvonen PJ, et al. (2009) $A B C G 2$ polymorphism markedly affects the pharmacokinetics of atorvastatin and rosuvastatin. Clin Pharmacol Ther 86: 197-203.

39. Ho RH, Kim RB (2005) Transporters and drug therapy: implications for drug disposition and disease. Clin Pharmacol Ther 78: 260-277.

40. Hoenig MR, Walker PJ, Gurnsey C, Beadle K, Johnson L (2011) The C3435 polymorphism in $A B C B 1$ influences atorvastatin efficacy and muscle symptoms in a high-risk vascular cohort. J Clin Lipidol 5: 91-96.

41. Keskitalo JE, Pasanen MK, Neuvonen PJ, Niemi M (2009) Different effects of the $A B C G 2$ c.421C>A SNP on the pharmacokinetics of fluvastatin, pravastatin and simvastatin. Pharmacogenomics 10: 1617-1624.

42. Tomlinson B, Hu M, Lee VW, Lui SS, Chu TT, et al. (2010) ABCG2 polymorphism is associated with the low-density lipoprotein cholesterol response to rosuvastatin. Clin Pharmacol Ther 87: 558-562.

43. Marcoff L, Thompson PD (2007) The role of coenzyme Q10 in statin-associated myopathy: a systematic review. J Am Coll Cardiol 49: 2231-2237.

44. Quinzii C, Naini A, Salviati L, Trevisson E, Navas P, et al. (2006) A mutation in para-hydroxybenzoate-polyprenyl transferase (COQ2) causes primary coenzyme Q10 deficiency. Am J Hum Genet 78: 345-349.

45. Puccetti L, Ciani F, Auteri A (2010) Genetic involvement in statins induced myopathy. Preliminary data from an observational case-control study. Atherosclerosis 211: 28-29. 